\title{
Relationship between community pride and participation needs in sustainable tourism development of Fishing Village: a case study of Samut Sakhon Province, Thailand
}

\author{
G. Pookaiyaudom \\ Management of Recreation and Tourism, Faculty of Sports Science, \\ Chulalongkorn University, Thailand
}

\begin{abstract}
This article investigates the relationship between community pride and participation needs in the sustainable tourism development of 'Fishing Village' in Samut Sakhon Province, Thailand. Pearson correlation was used to determine the relationship between these variables. In-depth interviews were also used to gather detailed data. The findings reveal that community pride regarding emotional bonding with other members and resource awareness have a strong relationship to the participation needs excluding willingness to sacrifice personal time. To conclude this research, this fishing village has the potential for sustainable tourism development as awareness of community pride connected to participation is the vital sign indicating an approach of sustainability. Thus, the sustainable development plan should indicate this community strength and encourage the knowledge in aspects of mutual needs for the willingness of working for the community. The paper ends with suggestions for future research.

Keywords: community pride, community participation, Fishing Village, Thailand.
\end{abstract}

\section{Introduction}

As a result of the acknowledgement of sustainable development from the publication of the Brundtland Report, Our Common Future by the World Commission on Environment and Development (WCED) in 1987, this concept has been integrated in many areas including tourism [1]. Consequently, sustainable tourism has been widely used in alternative forms such as ecotourism, responsible 
tourism and community-based tourism [2] as it is suggested as the appropriate approach for a long-term vision [1], by minimising the negative impact of tourism while maximising the benefit to locals [3] together with environmental and cultural conservation [4]. When engaging the principles of sustainable tourism community is an essential part, not merely to be considered as just a resource of the destination [5], but also in the need to engage in collaborative participation including the decision making process, in order to share the benefits and improve quality of life [6], although in some cases participation has been limited, proving difficult when facing obstacles and apathy [7]. Nevertheless, a number of studies such as [8-10] state that community pride is one of the key factors in encouraging the participation of a community.

In Thailand, sustainable development was initially underlined in the Eighth National Economic and Social Development Plan (NESDP) which started by emphasising on benefiting local people through community empowerment through training and skills development along with sustainable development [11]. Consequently, the concept has been adapted to tourism and numerous local areas have applied policies of sustainability by the community itself or at a larger level such as the local government or Sub-district Administrative Organisation (SAO). In this case, the Fishing Village of Samut Sakhon Province, Thailand has recently received an increase in popularity from domestic tourists as the location provides a unique glimpse of the traditional way of life of local fishermen and their families, offers coastal scenery along with Bryde whale sightseeing, has strong local wisdom and pride within the fishing community, and a united conservation in facing challenges such as coastal erosion [12]. To handle this increased influx of tourists and environmental degradation, Pantainorasingh SAO, a local government sector that takes charge of Fishing Village, initially drafted a tourism development plan concerning sustainability. Nevertheless, before making any tourism plan or implementing it, it has been suggested that a community assessment which includes their assets and needs is essential [13]. These needs, especially the need for participation in controlling and decision making, are key principles of sustainable tourism development [14]. Hence, this research aims to explore the participation needs in tourism management for the residents of Fishing Village. Moreover, as previously mentioned community pride will reinforce community participation, other objectives include the investigation of the connection between the fishing village's community pride and the participation needs required for effective tourism development, both an essential part of the community assessment. Suggestions are provided within this paper for a sustainable tourism development plan.

\section{Objectives}

- To explore Fishing Village's community participations needs for sustainable tourism development.

- To examine the relationship between the community pride and participation needs of Fishing Village. 


\section{Literature review}

Sustainable tourism development refers to the environmental, economic and sociocultural aspects of tourism development and an equitable balance established between these three dimensions to guarantee its long-term sustainability [4]. Numerous studies such as [13-15] refer to the principles and objectives of sustainable tourism development. They primarily focus on improving the quality of life for local people, along with protecting both the natural and built environment, whilst also offering a quality experience for visitors. There are also a number of principles relevant to sustainability; for example, resource accountability, stakeholder involvement, carrying capacity, women and minority empowerment [14]. However, since this paper aims to underline community participation based on community pride, the review will focus on the linkage of community participation with sustainable development.

In referring to community participation, Arnstein's review of participation degree [16] has been widely claimed. The review indicated three degrees of participation; non-participation, partial participation and degree of citizen power, in which to succeed to full citizen power, residents' empowerment of decision making is needed. While the decision making process is considered as the most crucial action of citizen participation [14], other processes include, implementation, benefit sharing and evaluation [17]. The significance of community participation towards sustainable tourism development covers local perspectives which are voiced, expressed in the design or planning and decision making, to be able to improve plans, decisions and service delivery; cohesive encouragement by sharing common goals and an opportunity for seeking collectively to assess problems and plan solutions together [8]. In other words, it is a sign of empowerment meaning locals are likely to share control and the benefits of the advantages of sustainability that is community well-being [6].

Such well-being not only provides the benefits of economic empowerment; for example, cash flow in community, employment opportunities and local ownership [14], but other perspectives linking to community pride are also vital as it crucially drives residents' involvement [10]. Community pride refers to the positive feelings of attachment and the emotional bond residents feel about their community and their feelings of satisfaction within the community [18]. Similar to the concepts of 'place attachment' [19] and 'sense of community' [20] which also refer to an affective bond between people and places that impact residents engagement within the community [9], and these will encourage community-level interaction in which residents would like to participate in activities. These take the forms such as participating in a community improvement project or working with other members of the community to try to solve local problems [21]. It is further explained that the concept interlinks with the 'psychology' of community empowerment that residents uphold self-esteem, to realise their own uniqueness and value their culture and natural resources as well as traditional knowledge [6]. Nonetheless, the level of community pride or attachment is possibly influenced by other determinants such as length of residence [9], satisfaction in local social ambience e.g. community spirit, friendliness and quality of local [22] and local social 
networks [23]. The high degree of community attachment can be perceived in the positive way that locals want to participate either to conserve their location's identity or willingly work to improve the well-being of residents [24]. In contrast, it is also seen as a negative impact of tourism due to concern over changes and problems that may dilute or divide their affective community [25], which could possibly lead to a negative or resentful attitude of residents towards tourism [26]. It also should be noted that even though residents have certain needs for participation in community; some obstacles lie outside these requirements for community involvement such as unsteady planning from local government [24], lack of financial resources, elite domination and corruption [7].

Following this overview of the literature, the researcher made the decision of choosing Fishing Village of Samut Sakhon Province as a case study due to the ongoing tourism plan draft. It has been known for its intellectual tourism which engages educational visitors wanting to experience the fishing community's way of life [27]. The location is also famous for its local wisdom towards the making of a unique shrimp paste, called 'Kapi' in Thai and also for local participation in coastal erosion prevention [12] through which community pride and attachment is reflected. Furthermore, it has received increased popularity from the bike tour route from Bangkok, in which Fishing Village is one of the featured tourism stops. Others come to indulge appetites for fresh seafood close to Bangkok, another significant reason for the rise in the number of visitors is the opportunity for spotting Bryde whales. Therefore, this study may be of benefit to planners in understanding local needs in participation including potentials and weaknesses regarding community pride in order to improve the tourism development plan in the future. The specific hypotheses in this research include (1) community participation needs in sustainable tourism development are acknowledged by residents in Fishing Village and (2) the community pride of residents has a relationship with participation needs.

\section{Methodologies}

This research had two stages; stage one was questionnaires and stage two was indepth interviews. The questionnaires developed by the researcher were employed with 306 samples from residents to achieve the objective of the study regarding community pride and the requirements for local participation. The content of the questionnaires was investigated for validity by three experts in tourism and was represented in the index of item objectives congruence (IOC) equivalent as 0.78 . Pre-testing of the research questionnaire was carried out by 30 respondents in the Khanom District, another community tourism destination in Thailand and the reliability of questionnaires was found by using Cronbach's Alpha Coefficient at 0.81 . To obtain further detailed information regarding community pride and resident participation, in-depth interviews were also conducted with two of the local administrators and a leader of community.

Opinions from the questionnaires was recorded using a Likert scale. Then data was processed by a statistical programmed software which indicated frequency, percentage, mean and standard deviation. Pearson correlation (two-tailed) was 
used to interpret the data in this section. Following this phase, data analysis from interpreted questionnaires and the in-depth interviews was categorised into the two themes of the research objectives, community participation needs and the relationship between community pride and participation need.

\section{Findings}

306 questionnaires were completed by residents from various professions (Fishermen, agriculturists, merchandisers, local administrators, housewives and retired people) who have lived in the fishing village for over 10 years. It was revealed that the gender ratio of participants was $67.6 \%$ male (207 of samples) to $32.4 \%$ female (99 of samples) with an age range from 20-50 years old and over. Over half of the respondents, $58.17 \%$ (178 of samples) acknowledged the sustainable tourism development but were unsure of a certain or definitive meaning, while $30.07 \%$ (92 of samples) knew and were able to explain the meaning. The rest of respondents, $11.76 \%$ (36 of samples), had no idea about the concept. Their opinions regarding participation needs are presented in Table 1, whist the opinions relevant to community pride as well as the correlation with participation needs are represented in Table 2. This data was grouped with the data from the in-depth interviews with local administrators and the community leader and the results are discussed using the three following themes.

Table 1: Fishing Village community participation's needs in sustainable tourism development.

\begin{tabular}{|c|l|c|c|}
\hline Items & Components of participation needs & $\overline{\mathbf{X}}$ & SD \\
\hline 1 & Needs in planning & 4.06 & .54 \\
\hline 2 & Needs in decision making & 3.97 & .62 \\
\hline 3 & Needs in partaking with activities & 4.32 & .68 \\
\hline 4 & Needs in evaluation & 3.85 & .65 \\
\hline 5 & Needs in benefits sharing & 4.09 & .56 \\
\hline 6 & Overall needs in participation & $\mathbf{4 . 0 6}$ & $\mathbf{. 4 1}$ \\
\hline
\end{tabular}

\subsection{Community participation needs in a sustainable tourism development}

It was revealed by the interviews that the fishing village has initiated a community awareness of fishery life style conservation under the community leader, $\mathrm{Mr}$ Somchai Subsripaiboon. The residents have been involved with activities in the community based on the strong relationship they have along with shared cooperative funds. The local administrators indicated that the local quality of life is improving with navigational sign post construction and infrastructure upscaling as well as tourism promotion. They also referred to the positive relationship between the local government and the community, such as resident involvement with projects organised by local administrators. Decision making within the community 
Table 2: The relationship between community pride and community participation needs.

\begin{tabular}{|c|c|c|c|c|}
\hline Items & Topics relevant to community pride & $\bar{X}$ & SD & $\mathbf{r}$ \\
\hline & Place attachment & & & \\
\hline 1 & Positive feelings towards community & 4.24 & .65 & .014 \\
\hline 2 & $\begin{array}{l}\text { Emotional bonding with other community } \\
\text { members }\end{array}$ & 4.15 & .65 & $.302 *$ \\
\hline \multirow[t]{2}{*}{3} & Place attachment raising to others & 4.21 & .68 & -0.23 \\
\hline & Values and resources awareness & & & \\
\hline 4 & $\begin{array}{l}\text { Community resources awareness i.e. natural } \\
\text { resources, culture, and local wisdom }\end{array}$ & 4.35 & .48 & $.498^{*}$ \\
\hline 5 & $\begin{array}{l}\text { Readiness to prevent loss and conserve } \\
\text { community resources from outsiders }\end{array}$ & 4.26 & .66 & 0.74 \\
\hline \multirow[t]{2}{*}{6} & $\begin{array}{l}\text { Participation in activities regarding resources } \\
\text { protection and conservation }\end{array}$ & 4.26 & .61 & $.222 *$ \\
\hline & Willingness of involvement with community & & & \\
\hline 7 & $\begin{array}{l}\text { Willingness to sacrifice your personal time to } \\
\text { work for community }\end{array}$ & 3.38 & .69 & .109 \\
\hline 8 & $\begin{array}{l}\text { Involvement with community work when } \\
\text { others need your help }\end{array}$ & 3.44 & .55 & -0.89 \\
\hline 9 & $\begin{array}{l}\text { Convincing other members to work for } \\
\text { community }\end{array}$ & 3.44 & .50 & $.133^{*}$ \\
\hline
\end{tabular}

exists with regard to fishing and living matters but is not yet concern with tourism. In response to sustainable tourism development, according to Table 1, the results indicated that respondents were likely to agree concerning the participation needs in each item which is represented as an overall average in item $6(\bar{X}=4.06, \mathrm{SD}$ $=.41$ ). The item respondents agreed the most concerning item was item 3 , needs in partaking with activities $(\bar{X}=4.32, \mathrm{SD}=.68)$. Item 5 , needs in benefit sharing and item 1, needs in planning, followed respectively $(\bar{X}=4.09, \mathrm{SD}=.56$ and $\bar{X}$ $=4.06, \mathrm{SD}=.54)$. Item 2 , needs in decision making, which is the most critical part in participation came in the fourth place $(\bar{X}=3.97, \mathrm{SD}=.62)$, and the last was item 4 , needs in evaluation $(\bar{X}=3.85, \mathrm{SD}=.65)$. When referring to the Standard Deviation (SD) as a measure of dispersion of each item, it is representational of the low dissemination of data resulting in the agreement towards a similar single direction. The community leader stated via interviews that residents in the community would also like to participate in a sustainable tourism development, however there is the problem that no such plan currently exists. 


\subsection{Relationship between community pride and community participation needs}

Considering community pride, data from the interviews indicated that locals were proud of their fishing lifestyle. Apart from the continued existence of the fishing village with its high basement-styled wooden houses, to sustain the fishing trade and traditional way of life, locals continue their wisdom and customs through the making of local shrimp paste 'Kapi'. This was represented and has been considered as the main career for housewives under the female leader, Mrs Chailai Ributr. While the other leader, Mr Somchai would demonstrate fishing every weekend to young locals in order to acknowledge the values, traditions and skills as well as create an opportunity for an optional job in the future. The community leader emphasised the closeness of the neighbourhood as a collective influence for participation in community. This was also reported by the questionnaires analysed in Table 2, residents agreed to having community pride in their locality and a resource awareness to similar levels, the item respondents agreed to the most was item 4 , community resource awareness $(\bar{X}=4.35, \mathrm{SD}=.48)$.

This is continually demonstrated in the previous table as the item grouping concerning values and resource awareness; participation in activities regarding resource protection and conservation and community resource awareness, show the strongest levels of community agreement. Following that order to a slightly lesser scale is the item grouping connected to place attachment; positive feelings towards community, place attachment raising to others and emotional bonding with other community members. In contrast, respondents agreed the least to questions under the willingness of involvement with community section, which contained willingness to sacrifice personal time to work for community ( $\overline{\mathbf{X}}=3.38$, $\mathrm{SD}=.69)$, involvement with community work when other needs $(\overline{\boldsymbol{X}}=3.44$, SD $=.55)$ and convincing other members to work for community $(\bar{X}=3.44$, SD $=.50$ ). Similar to Table 1, each item revealed a low Standard Deviation (SD), hence the agreement of respondents seem to be in accordance with each other. After investigation of the results of the relationship between community pride topics to participation needs by the indicated correlation (r) with a statistical significance at 0.05 , it was revealed that 4 out of 9 items unearthed emotional bonding with other community members $(\mathrm{r}=.302 *)$, community resource awareness $\left(\mathrm{r}=.498^{*}\right)$, participation in activities regarding resources protection and conservation $(\mathrm{r}$ $=.222 *)$ and convincing other members to work for community $(\mathrm{r}=.133 *)$. Matched with the data from the questionnaires, it was also revealed from the interviews that residents put more effort towards resource degradation prevention. With the village being located near the coast, where coastal erosion was occurring, there were collaborative actions from locals to protect their community by helping each other construct bamboo barriers to reduce the impact of the strong waves that have been eroding the seashore and destroying residential areas. Furthermore, due to the loss of mangrove areas around the village caused by natural disaster as well as coastal erosion, the local government; Puntainorasingh SAO also took the 
action of planting mangrove forests and asked local students to join in, in order to raise community value awareness.

\subsection{Critiques towards sustainable tourism development in Fishing Village}

Regarding the interviews, questions relevant to the obstacles of sustainable tourism development were asked and informed the research of two main issues. The first one was the lack of participation by the new generation, as the circumstances have changed for the well educated new generation, the majority of which have at least graduated from secondary school. They tend to work in other careers that generate more income. Moreover, it was stated by parents that they would prefer their children to work in other careers than being fishermen although they remain proud of their lives and community. It was further explained that this was also due to the unstable nature of the income derived from fishing and the associated risks with ventures out into deeper waters. Consequently, it is foreseeable that the lack of new generation participation may impact the community severely in the future and any plans for sustainable tourism development. The second aspect was the limited knowledge of sustainable tourism, based on interviews, it was revealed that a number of locals perceived tourism as an income influx involving mass tourists. When referring to tourism, locals were likely to make links to the quantity of tourists rather than considering the quality of different tourist types. Such apparent lack of awareness and knowledge of low impact tourism planning to tradition, environment and way of life, may have a detrimental effect on the locals concept of sustainable tourism development and their eagerness to participate in it.

\section{Discussion and conclusion}

The results of this research indicated a match with the hypotheses. Firstly, it has been revealed that the community would like to participate in sustainable tourism development. Based on Arnstein's model, residents hold a degree of citizen power as they are empowered by independent decision making which is representative of the type of crucial action needed for citizen participation [6]. In this regard, as a sustainable tourism development plan has been drafted, this community participation from the village can be the essential part that encourages sustainability. Nevertheless, by reviewing the results it can be seen that although the level of overall need for participation in tourism was high $(\bar{X}=4.06$, SD $=.41$ ), the decision making needs which were the essential part was not the topic in which the respondents agreed the most $(\bar{X}=3.97, \mathrm{SD}=.62)$. This may imply that they may have limited knowledge and a lack of information regarding sustainable tourism development, respondents may also feel unsure of decision making and details relevant towards this. Hence, local administrators should encourage resident awareness towards all aspects of sustainability in tourism particularly those that have links to local decision making. 
Secondly, community pride has been shown to be significant in this research, being perceived in various aspects. First, the fishing way of life, by which most of the residents in the location earn their living, the location is hence aptly called 'Fishing Village' with the constructions of high basement-styled wooden houses and it welcomes many visitors that travel there to experience the villages unique identity amidst its traditional architecture and customs. Next, it is the traditional knowledge of making local Kapi, not only in regards to local wisdom but it also represents a type of sustainability, reinforcing further aspects such as the empowerment of women [14]; with housewives that are able to obtain an income from their skills, craft and produce. Finally, the natural resource awareness, they are proud of their location which is comprised of fisher lifestyle households, the coast and is the location of Bryde whales. They also acknowledge the problems caused by coastal erosion to the extent that they launched a collaborative action for erosion prevention. Other key elements include the passing on of skills and traditional knowledge to the next generation, with local children learning the local fishery lifestyle at the weekends giving them pride in their community. As community pride refers to the positive feelings of attachment and emotional bonds residents feel about their community and their feelings of satisfaction within the community [28], such is the case revealed in this research. According to the results, aspects of community pride in values, resources awareness and emotional bonding with other members were essential pillars relevant to community participation needs. These feelings of bonding to others also drove participation in activities regarding natural resources protection and conservation by convincing individuals to work together for the sake of the community. In this case, not only does it represent the closeness between locals, it might also outline the significant roles of the community leaders reinforcing local involvement. Nevertheless, some of the viewed aspects of willingness of involvement and place attachment limited relationship to participation needs. Regarding willingness of involvement, it may be limited in this area due to the fishing way of life which involves sailing out for a living. Hence, it is difficult for any fishermen who needs to be out of village to work, from days to weeks, to involve themselves or commit to community activities. While there were other items that respondents highly agreed on which are; the place attachment in the aspect of positive feeling towards community, pride awareness raising and readiness to protect and conserve community resources from outsiders, they may be less significant when compared to other statistical significant factors driving locals involvement such as emotional bonding to other members, values and resource awareness.

To conclude the study, the fishing village of Pantainorasingh SAO, Samut Sakhon Province has potential for development as a sustainable tourism destination as it revealed full citizen power involvement based on community pride. Hence, the local administrators should encourage and sustain this pride by having on ongoing project of activities raising pride awareness. Some critiques were found such as the limited knowledge of sustainable tourism development as well as the possibility of the local generation not inheriting and keeping the traditional customs and ways of living. The local administrators should further reinforce all aspects of sustainability to residents, especially the components of 
participation; planning, involvement, evaluation, benefit sharing including decision making, a vital component in community empowerment. The welcoming and encouragement of quality and appropriate tourist types is also needed. With sustainable tourism in a small-scale area it is essential to cultivate a small-scale approach and create local awareness for the promotion of the quality of tourist rather than the quantity. Moreover, given the boating lifestyle of local fishermen, the tourism plan and activities would do well to focus on training local women, the majority of which are housewives, and may potentially be able to hold other jobs and key positions within the village. It is important that the next generation gets involved with aspects of tourism destination. Apart from learning local fishing, coastal erosion prevention, residents may also train and encourage young members of the community to act as local guides or representatives to further raise pride and emotional bonding.

\section{Suggestion for future researches}

This research only focused on the relationship of community pride to community participation needs. As sustainability is comprised of a variety of factors, including collaboration between government, stakeholders and locals, future research may study other aspects reinforcing sustainability in order to contribute a more complete sustainable tourism development plan for this location. Moreover, the various characteristics of respondents may be analysed in the future in order to find out their internal factor driving participation needs.

\section{Acknowledgements}

The researcher would like to thank Chulalongkorn University for being a sponsor of this research project and also the local administrators, local leader and residents in Fishing Village, Pantainorasingh SAO, Samut Sakhon Province who sacrificed their personal time for interviews and to complete questionnaires.

\section{References}

[1] Butler, R.W., Sustainable tourism: a state-of-the-art review. Tourism Geographies, 1(1), pp. 7-25, 1999.

[2] Beeton, S., Ecotourism: A Practical Guide for Rural Communities, Landlinks Press: Melbourne, 1998.

[3] United Nations Conference on Sustainable Development Non-Government Organisation Steering Committee, Tourism and Sustainable development: A Non-Governmental Organisation Perspective (19-30 April), 1999.

[4] World Tourism Organisation, Tourism Highlights Edition 2004, World Tourism Organisation: Madrid, 2004.

[5] Murphy, P.E., Tourism: A Community Approach, University Press Cambridge: London, 1985. 
[6] Scheyvens, R., Tourism for Development: Empowering Communities, Prentice Hall: Essex, 2002.

[7] Tosun, C., Limits to community participation in the tourism development, process in developing countries, Tourism Management, 21, pp. 613-633, 2000.

[8] Sanoff, H., Community Participation Method in Design and Planning, John Wiley and Sons Inc: New York, 2000.

[9] Manzo, L.C. \& Perkins, D.D., Finding common ground: the importance of place attachment to community participation and planning. Journal of Planning Literature, 20(4), pp. 335-350, 2006.

[10] Flint, R.W., Practice of Sustainable Community Development: A Participatory Framework for Change, Springer: New York, 2013.

[11] Office of the National Economic and Social Development, The Eighth National Economic and Social Development Plan. Office of the National Economic and Social Development: Bangkok, 1996.

[12] Suakhong, S. Fishery Way of Life Conservation, A Case of District Pantainorrasingh, Samut Sakhon Province (Independent Study), Ramkhamhang University, 2012.

[13] Choi, H. \& Sirakaya, E., Measuring resident's attitude toward sustainable tourism: development of sustainable tourism attitude scale. Journal of Travel Research, 43(4), pp. 380-394, 2005.

[14] Telfer, D. \& Sharpley, R., (eds). Tourism and Development in the Developing World, Routledge: New York, 2008.

[15] Bramwell, B. \& Lane, B., Tourism Collaboration and Partnerships, Politics, Practice and Sustainability, Channel View Publications: Clevedon, 2000.

[16] Arnstein, S., Ladder of citizen participation. Journal of the American Institute of Planner, 4, pp. 216-224, 1969.

[17] Cohen, J.M. \& Uphoff, N.T., Effective Behavior in Organizations, Richard D. Irwin Inc, New York, 1980.

[18] Sirgy, M.J., The Psychology of Quality of Life: Hedonic Well-being, Life Satisfaction, and Eudaimonia, Springer: Blacksburg, 2012.

[19] Altman, I. \& Low, S.M. Place Attachment. New York: Plenum, 1992.

[20] Aref, F., Sense of community and participation for tourism development. Life Science Journal, 8(1), pp. 20-25, 2011.

[21] Theodori, G.L., Community attachment, satisfaction, and action. Journal of the Community Development Society, 35(2), pp. 73-86, 2004.

[22] James, B., Community Attachment: Determinants, Indicators and Measures, Centre for Research, Evaluation and Social Assessment: Wellington, 2004.

[23] Wu, M \& Tsa, Y., Effects of socio-spatial factors on community attachment: a study of the urban community in Shihlin. Journal of Population Studies, 36, pp. 1-36, 2008.

[24] Pookaiyaudom, G., A Comparative Analysis of International and Domestic Tourists' Perceptions of Community-Based Tourism: The Case of Pai, Thailand (Doctoral Dissertation), University of Central Lancashire, 2014. 
354 Ecosystems and Sustainable Development X

[25] McCool, S. F. \& Martin, S. T., Community attachment and attitudes toward tourism development. Journal of Travel Research, 32(3), pp. 29-34, 1994.

[26] Andereck, K.L., Valentine, K.M., Knopf, R.C. \& Vogt, C.A. Residents' perceptions of community tourism impacts'. Annals of Tourism Research, 32 (4), pp. 1056-76, 2005.

[27] Pantainorasingh Sub-district Administrative Organisation, www.pantainorasingh.go.th 